\title{
The Construction and Information Service Mode Exploration of the Handheld Smart Library Platform based on Web Certification
}

\author{
Zeng Jianming, Song Xiaoli \\ Jiangxi Modern Polytechnic College
}

\begin{abstract}
As the content of traditional culture, library now is also changing dramatically. With the propulsion of wireless network technology, database technology, software engineering, etc, the research to the digital library continues to innovate. Under the condition of the rapid development of mobile wireless, the research and development and design of the mobile digital library arises at the historic moment. This paper introduces the main technology of the mobile digital library based on mobile Web, and carries on the detailed design of mobile digital library through the analysis of the feasibility and demand of the digital library based on the mobile Web, and then carries out coding and implementation to the system. Based on the above, the author summarizes the results in the process of system design and implementation and the future development direction.
\end{abstract}

\section{Key words-Digital library system, Web, Mobile, Client}

\section{INTRODUCTION}

At present, as the development of computer technology and the increase of the wireless network speed, great changes have taken place in people's communication way. Mobile communications and mobile 3G, 4G networks have become the essential way of communication. Under $3 \mathrm{G}$ and $4 \mathrm{G}$ network, the speed of mobile network has been greatly improved, meanwhile, the high-speed wireless network also brings a lot of mobile network information service. Mobile network indeed changes our way of life, the service brought by the mobile network is moving into every field of people's life and the mobile network is still in constant completing its self-improvement service content and service group. A new mobile Internet world has shown in front of us.

Libraries provide readers with rich reading resources, and with the development of computer technology, the digital library also provides readers with book information services in the form of information. Under the impetus of the rapid development of mobile network technology, the application of the digital library is also quietly changing. Digital library system, which is based on mobile network combines the modern computer science and technology, the wireless network technology and database management system technology, is growing. Mobile digital library under the network system provides readers with a more extensive mass library information and resources and makes readers can access all kinds of book information anytime and anywhere, which greatly improving the service ability, service quality and service levels of traditional library.
Under the background of the development of the mobile Web and mobile terminals, the new mobile Internet terminals has a rapid development, which provides a larger development space for the application of the mobile Internet industry, such as "handheld bank", "handheld stock", "handheld map" and many other mobile applications, which have achieved some results. However, the research and development of the digital library system based on Web is still in the initial state with a lot of research on space.

\section{THE OVERVIEW OF MOBILE WEB}

In Web application system architecture, which often referred to the browser/server structure (B/S structure), the user uses a Web browser as a client to access Web site on the server, the browser downloads the site data, and caches the data in the client. Browser displays site page and the user operates in the browser.

Comparing to $\mathrm{C} / \mathrm{S}$ system architecture, from the perspective of the system architecture of $\mathrm{B} / \mathrm{S}$ model, Web application has the following several advantages :

(1)It has nothing to do with the client platform. Web applications run in the browser, so that no matter what kind of computers, what kind of hardware configuration and what kind of operating system, as long as the user's browser supports Web standards and connects the client to the Internet, the user can run Web applications and visit Web site.

(2)The system is easy to maintain. We deployed the applications on remote server. When reissuing or updating the application, it is only needed to change the application on server without changing the local client. Just input the address in the browse in the client, the user can access the latest version of the Web application of the server.

(3)User data is easier to manage. In the $\mathrm{B} / \mathrm{S}$ structure system, the user data is centrally stored on a remote server, which can be directly and uniformly operated and managed on the server. The system has no need to operate or manage the user data in a single client.

\section{THE DESIGN OF THE HAND-HELD LIBRARY SYSTEM}

\section{OF COLLEGES AND UNIVERSITIES}

After 2014 when China issued 4G licenses, mobile network transmission speed has greatly improved and the popularity of smart phones make mobile phone library's service function be more diversified and personalized. Currently, mobile phone library cannot only provide the traditional services, such as renewing books, reservation, 
duration reminding, some characteristic services, such as reference and consulting, online reading, location query, video demands can also be achieved by mobile phone library. Summarizing the research literature of the mobile phone library services at home and abroad, this paper divides the mobile phone library services into five categories, such as information notifications, querying and searching, interactive communication, mobile reading and my library. The mobile library services can be listed as follows which are shown in Fig .1.

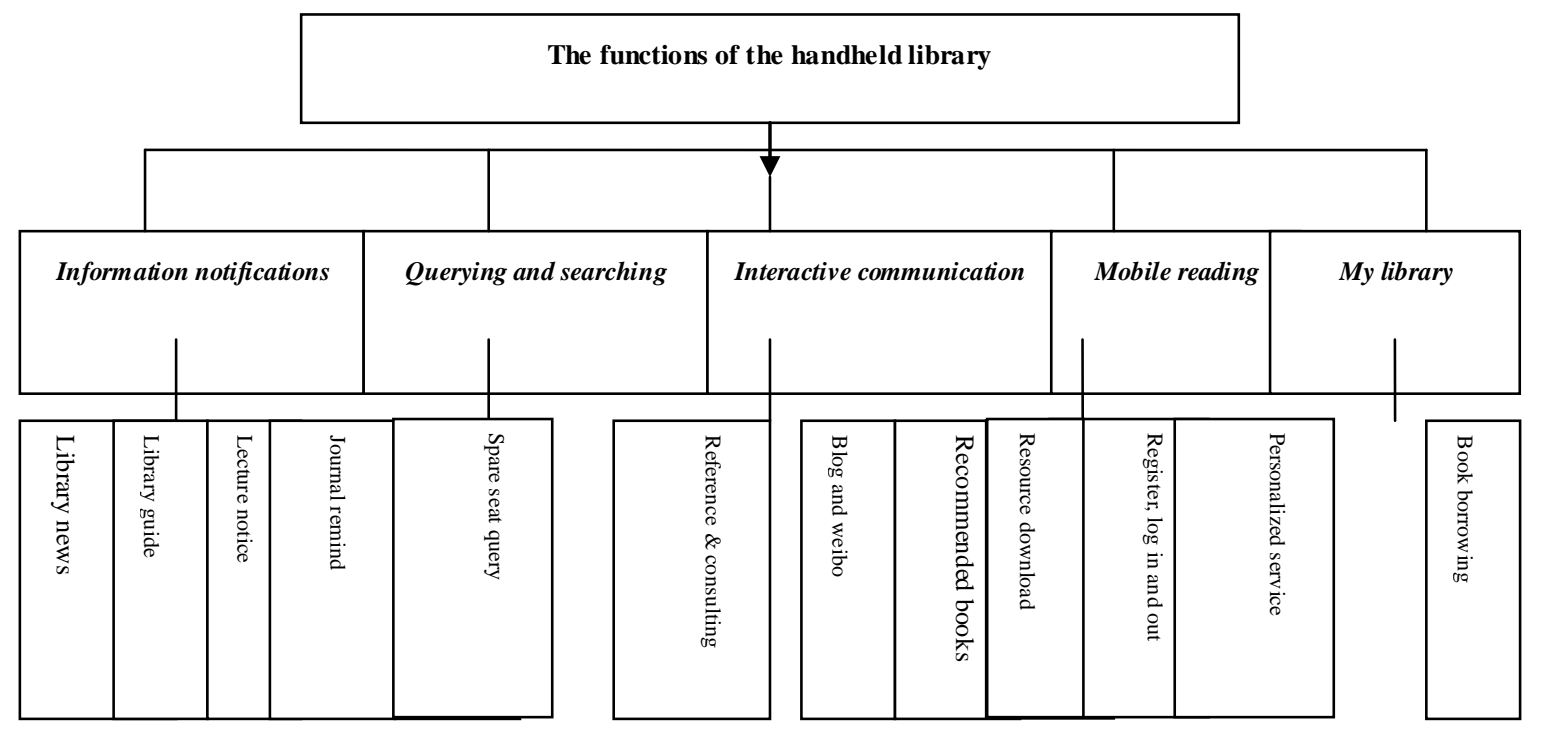

Figure 1.The service functions of the handheld library

\section{SYSTEM STRUCTURE DESIGN}

The system structure of the digital library system based on mobile Web can be mainly divided into three levels, such as data processing layer, service display layer and thin client layer. The system structure is shown in Fig. 2 .

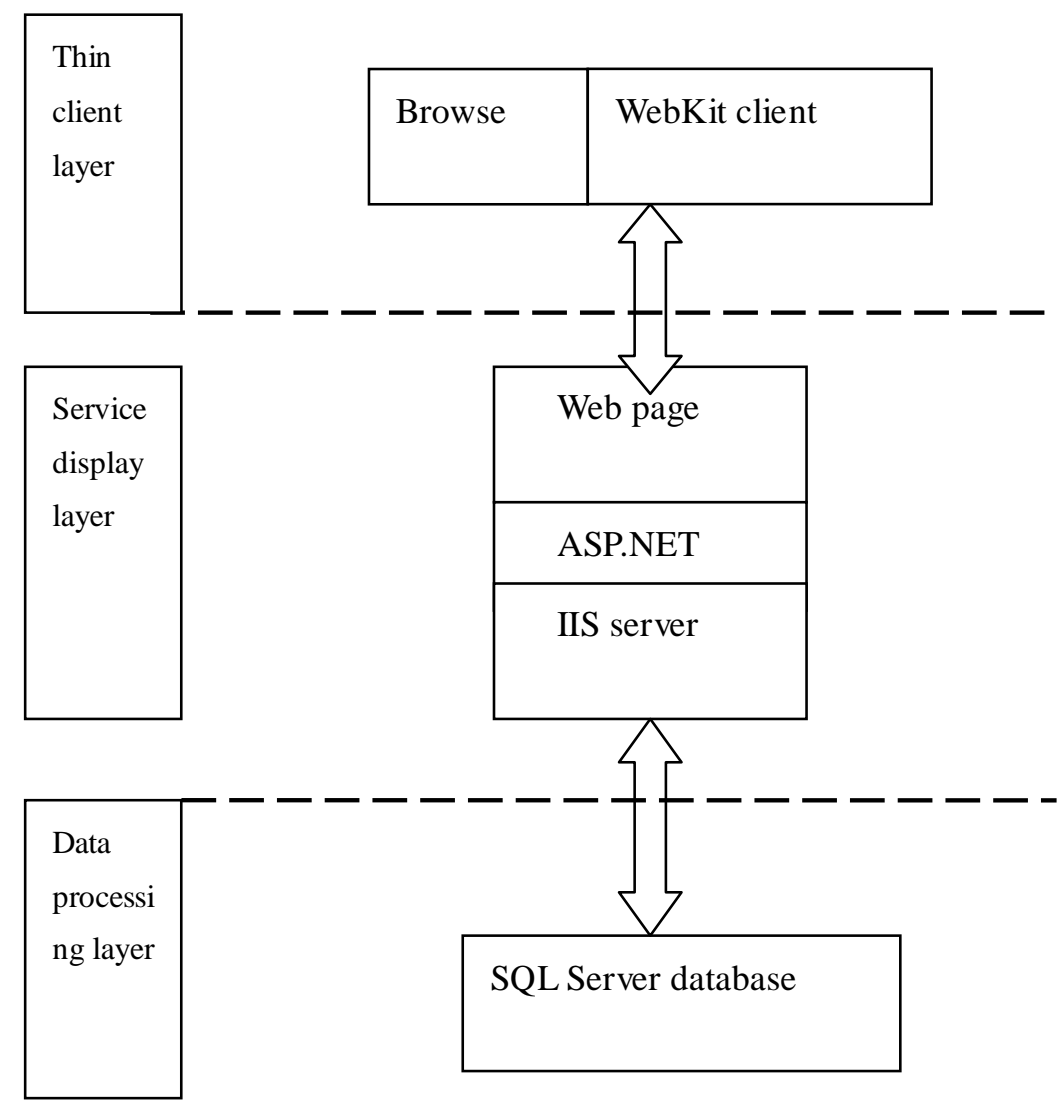

Figure 2. The three layers structure of the system 
The three layers structure of the system are as follows:

(1)The thin client of the system provides the shell of loading system websites. The client program can be made up by both platform's own browser and cross-platform WebKit software. The user can access system website cross platform and side by client layer and carry out the corresponding operation. This layer is mainly achieved through the development tools of different platform.

(2)Service display layer provides the system interface of the website application, which is also known as system presentation layer. The website application consists of users' query operation pages. Different users access the system with different permissions to achieve different functions. The behaviors of this layer are mainly achieved by Web and script of ASP.NET showcases, and ASP.NET is deployed on IIS server.

(3)The main task of data processing layer is the interaction between ASP.NET and the database. It is located on the bottom of the three layers. This layer is to achieve the operations of data querying, inserting, deleting and modifying in the library system. Data processing layer provides data service for service display layer. It queries or maintains the data in database according to the requires of service display layer.

\section{V.CONCLUSION}

Starting from the analysis of the current development situation of mobile digital library and the application of mobile Web technology, based on the study and research to ASP.NET technology, IIS server, Android platform and other related technology, this paper designs and implements the mobile digital library system by the mobile Web development technology. The main tasks and results of the paper are as follows:

(1)Carry out deep analysis and research to the application of mobile Web technology in digital library information system.

(2)Analyze the technology advantages of ASP.NET development, Web and IIS built server and discusses the key technologies of the digital library in details.

(3)Carry out systematic feasibility analysis, system requirements analysis, system architecture design, database design and system design in details to the digital library system based on mobile Web, on the basis of which, the mobile digital library is developed.

(4)After the completion of each function module, carry out function module display to the system.

\section{ACKNOWLEDGEMENTS}

This work was supported by Jiangxi modern vocational education group: the apple of wisdom library based on Web authentication platform construction and information service mode

\section{REFERENCES}

[1] Aittola, Markus, T. Ryhänen, and T. Ojala. "Smartlibrary Location-Aware Mobile Library Service." Human-Computer Interaction with Mobile Devices and Services 2795(2003):411-416.

[2] Aittola M, Ryhänen T, Ojala T. Smartlibrary - Location-Aware Mobile Library Service[J]. Human-Computer Interaction with Mobile Devices and Services, 2003, 2795:411-416.

[3] Paterson, Lorraine, and B. Low. "Student attitudes towards mobile library services for smartphones." Library $\mathrm{Hi}$ Tech 29.3(2011):412-423(12).

[4] Liu, Hongli. "The Current Situation and Trends of Mobile Library Study in China." Journal of the National Library of China (2012).

[5] Peng, Fei, and S. C. Wang. "Research on the Current Issues and Development of Mobile Library in China." Research \& Exploration in Laboratory (2014)

[6] Yufang, W. U. "Mobile Library Information Services Based on 3G." Journal of Zhanjiang Normal College (2012).

[7] Guo S M, Liu Y F, Economics S O, et al. Analysis of the Mobile Library Research Hotspots in China Based on Knowledge Mapping[J]. Information Science, 2014.

[8] Liang, Jian Fei. "Information service in mobile library of China:A review of literature." Chinese Journal of Medical Library \& Information Science (2013).

[9] Cui, Xiu Yan. "The Research of Function and Significance about Mobile Library." Journal of Library \& Information Sciences in Agriculture (2013).

[10] Jun-Tao M A, Dong Q S, Huang W, et al. Mobile library theory and its application research:A review[J]. Chinese Journal of Medical Library \& Information Science, 2012.

[11] Davidson, Glenn, and D. Dan. "Selection criteria for mobile library collections." Collection Building 28.2(1978):51-58.

[12] Shi, Guohong, and Y. Ma. "A Research of Mobile Library Usability's Effect on Service Quality." Research on Library Science (2015). 